\title{
UNA CRÍTICA SOBRE LA LABOR DOCENTE A PARTIR DE: DON SEGUNDO SOMBRA
}

\author{
GessicaGiohanna Espejo Velásquez. \\ Licenciatura en español y literatura \\ Universidad Industrial de Santander
}

\begin{abstract}
Proemio
El objetivo principal de este ensayo es mostrar mi perspectiva acerca de la labor del docente en la sociedad a través de la novela Don Segundo Sombra vista y analizada como un texto de educación y formación del ser. A lo largo de este trabajo haré un recorrido por dicha novela para analizar la participación y función de personajes como Mercedes, Asunción, Don Segundo y Fabio Cáceres, de este modo mostraré cómo se desarrolla allí la labor del docente y presentaré, así, algunas ideas que buscan una reorientación en el modo de afrontar la educación. Para sustentar la concepción de la educación que aquí propongo me basaré principalmente en los planteamientos del filósofo y pedagogo colombiano Estanislao Zuleta, quien, junto con los aportes de Aníbal Ponce, Juan José Arreola, William Ospina, Gaston Bachelard y Ernesto Sábato, me permitirá sustentar y evidenciar las problemática educativas actuales.
\end{abstract}

"Ensefiar es incitar a amar Lo que uno desea..." (Estanislao Zuleta)

"El ser humano aprende En la medida en que participa En el descubrimiento y la invención"

(Ernesto Sabato)

Como estudiosa de la enseñanza del español y literatura en la secundaria es de mi interés hablar de la pedagogía. Por esta razón, busco por medio de este trabajo encontrar nuevas perspectivas que fortalezcan mi futura labor docente y contribuir un poco a esta labor del docente. Para ello me baso en la literatura, que es mi campo de desempeño, y en el planteamiento que hacen diferentes autores sobre la labor del docente en la formación de los jóvenes que ingresan a la escolaridad. Estas líneas, aunque no pretenden ser un decálogo del buen educador, se presentan como un acercamiento crítico acerca de su labor.

\section{Don Segundo Sombra y la educación}

En la novela Don Segundo Sombra, escrita por el argentino Ricardo Güiraldes, se muestra la formación de un gaucho, Fabio Cáceres, quien aprende a vivir como resero gracias a la orientación didáctica de este oficio por parte de Don Segundo, su padrino. Aunque la problemática central de la obra no es la educación, me sirvo de ella para este trabajo porque encuentro en su desarrollo ideas muy pertinentes acerca de la formación del ser. Por otra parte, la idea de tomar como base esta obra literaria surge de las apreciaciones y reflexiones pedagógicas y epistemológicas del Maestro Estanislao Zuleta y, en 
especial, la forma como él aprecia la literatura y su relación con el entorno educativo.

Para abordar la temática educativa en esta obra de Ricardo Güiraldes tomo la pampa, lugar en donde se desarrolla la novela, como aquel entorno que representa la escuela: el salón de clase. Del mismo modo, Fabio Cáceres, el protagonista de la obra, como el personaje indispensable para que se dé el comienzo de un proceso pedagógico y en este sentido es quien representa al estudiante. Del mismo modo, las tías de Fabio Cáceres y Don Segundo Sombra representan dos tipos de educadores y por ende dos formas de asumir la educación. En primer lugar, se observa en la obra una educación represiva, en donde el castigo y el miedo son dos factores principales. Esta manera de educar al individuo es la que utilizan Mercedes y Asunción, tías del muchacho, quienes buscan por medio de los golpes y de la religión formar correctamente a su sobrino Fabio Cáceres: "Ya mis tías no hacían caso de mí sino para llevarme a misa los domingos y hacerme rezar de noche el rosario. En ambos casos me encontraba en la situación de un preso entre dos vigilantes, cuyas advertencias poco a poco fueron reduciéndose a un simple coscorrón" (Güiraldes, 1985, p. 20 - 21). En esta cita aparecen dos factores determinantes en la educación actual, los cuales se convierten en un obstáculo para su mejoramiento. El primero consiste en la intervención de la Iglesia en la educación de todos los estudiantes, ya sean de primaria 0 de secundaria. Esta educación no solo consiste en la existencia de una materia designada para la enseñanza de la religión, más exactamente del culto católico, sino en aquella idea que tienen los docentes de que existe dentro del aula de clase alguien que tiene el poder y alguien que debe ser sometido, en otras palabras, la creencia de que el profesor tiene la verdad y la razón absolutas sin dar cabida a la discusión y a la toma de diferentes posiciones frente a las temáticas abordadas dentro de la clase. Ante esta situación Estanislao Zuleta dice lo siguiente:

Tal es el caso del análisis de la educación católica que ha primado y sigue primando en nuestra educación, así se denomine de manera distinta y cuya característica es la de ser una educación de la intimidación, en la cual quien no esté de acuerdo o se someta está condenado, es un hereje. Para este tipo de educación resulta incómodo el individuo que introduce la duda, que desarrolla la capacidad de dudar, que se hace y hace preguntas a otros, lo cual es esencial para que el ser humano se forme, para que pueda existir efectivamente una relación educativa creadora. (1995, p.113).

Contamos, entonces, con una educación beatificada que lo que hace es estancar la formación del individuo, pues lo limita al no permitirle desarrollar su capacidad de ser pensante y lo convierte en un ser fácilmente manipulable, que actúa de determinada manera sin saber por qué, simplemente porque en el colegio le enseñaron a seguir una reglas y una moral que por ningún motivo puede quebrantar. De este modo, de los centros educativos se gradúan personas que no son capaces de sustentar su posición frente a un tema, que no son capaces de dudar de lo que la sociedad les ofrece, debido a que fueron formados dentro de un régimen estricto que no les permitía contrariar las decisiones del educador. Incluso, el mismo docente hace parte de esa gran mayoría de personas que no son capaces de pensar por sí mismas y que se pasan toda la vida siguiendo normas y leyes; las cuales no se atreven ni siquiera a analizar.

Quizás muchos lectores se escandalicen a leer que los docentes no son capaces de pensar por sí mimos, por dicha razón, antes de seguir hablando de los factores determinantes en la educación de las tías de Fabio, me detendré en esta afirmación. ¿Cuántos de nosotros no tuvimos profesores que se pasaban las dos horas de clase llenando toda la extensión del tablero, sin poner atención a las inquietudes de sus estudiantes?, ¿cuántos no tuvimos que transcribir páginas enteras?, o ¿cuántos no escuchamos decir ante una inquietud "ahorita no estamos hablando de eso"? Estas son evidencias de la falta de carácter racional que afecta al colectivo educativo. Pero para ser más clara y, por qué no, convincente, me referiré a las cartillas escolares, sí, esos libros costosísimos que muchos padres de familia hacen el esfuerzo de comprar para que sus hijos obtengan bueno resultados académicos, porque para eso sirven, para obtener buenas calificaciones. En diferentes oportunidades he visto cómo los niños transcriben páginas enteras, convirtiendo sus cuadernos únicamente en una copia de sus libros escolares. Ante esta situación es evidente la pregunta: ¿qué pretende el docente con su copie y pegue? Quizá su única preocupación 
sea desarrollar la rapidez al escribir y no enseñar a comprender los diferentes conflictos sociales que han existido a través de la historia o las concepciones del mundo que tenían las civilizaciones indígenas, por mencionar algunas temáticas que se pueden abordar a partir de una cartilla, llámese Ejes Sociales o Retos lenguaje. En este caso "el Amigo lector sería con gusto reemplazado por una severa advertencia: ¡Atención, alumno! El libro plantea sus propias preguntas. El libro manda" (Bachelard, 1979, p. 29). Eso es lo que sucede en clase, el docente permite que la cartilla domine y se convierta en el recetario de su labor, porque sus cinco años de universidad no le permitieron desarrollar su propio espíritu racional para organizar una clase, y se conforma con seguir el índice de la cartilla 0 , como en el caso mencionado anteriormente, con hacer una copia de la misma.

Sin embargo, esto no solo pasa con las cartillas, también sucede con los textos literarios. Para este ejemplo también recurro a las actividades de los colegios que prestan sus espacios para el desarrollo de la práctica docente, en donde uno encuentra actividades como los que a continuación detallo: buscar las palabras desconocidas en El principito 0 en los poemas de Jairo Aníbal Niño, memorizar poemas o hacer en repetidas ocasiones crucigramas o sopas de letras con determinadas vocablos extraídos de las respectivas lecturas. Sin duda, esta es otra muestra de la afirmación de que muchos educadores no son capaces o no quieren pensar por sí mismos, digo muchos porque afortunadamente no son todos, ya que he conocido en mi vida de bachiller y de universitaria seres realmente comprometidos con su oficio. Sin duda, "el libro es una magnífica ayuda, cuando no se convierte en un estorbo. Si Galileo se hubiese limitado a repetir los textos aristotélicos (como uno de eso muchachos que ciertos profesores consideran "buenos alumnos"), no habría averiguado que el maestro se equivocaba sobre la caída de los cuerpos" (Sábato, 1996, p. 90).

Ahora bien, después de esta breve digresión, retomo la idea extraída de la educación ejercida por Mercedes y Asunción, en donde mencionaba la religiosidad como un primer elemento trascendental, me permito ahora mencionar el segundo factor determinante presente en la anterior cita tomada del texto de Ricardo Güiraldes, que consiste en la sumisión del otro por medio del castigo. Las tías de
Fabio Cáceres recurren a los regaños y a los golpes para hacer evidente su autoridad y obtener del él el comportamiento que ellas desean. El rechazo de Estanislao Zuleta ante esta forma de enseñanza es muy claro, ya que, según él, "hay una relación necesaria, generalmente mala, entre educación y autoridad. La autoridad no ha sido nunca buena educadora. Esto ya lo sabían los griegos. La educación no es ni debe ser necesariamente doméstica. Cuando la educación no es más que convertir al otro en la imagen que nosotros tenemos del deber ser, es una mala educación" (1995, p. 116). Idea con la que estoy totalmente de acuerdo, pues el docente no debe exigir el respeto por parte de sus alumnos, no debe tratar de imponerse por medio de gritos, de golpes y de amenazas, ya que el respeto y la admiración se ganan a través de la manera como el docente guíe al estudiante hacia el conocimiento. Además, "todo autoritarismo forma seres sometidos y resentidos, nunca seres libres e iguales" (Ospina, 2012, p. 48), en este sentido, la educación debe permitir la libertad, es decir, el docente no debe pensar que está modelando plastilina, sino ser consciente de que está ante seres que pueden pensar y elegir cómo ser o proceder. En el aula no nos encontraremos con seres vacíos, a los que debemos embutirles todo el conocimiento, por el contrario, nos encontramos con individuos que ya tienen una cultura y unas ideas de vida marcadas, con los cuales debemos mediar para lograr de ellos una mejor intervención en la sociedad. De este modo en el aula de clase "la única autoridad que podemos consentir es la que se desprende de la capacidad, de la categoría intelectual, de los dones del conocimiento obtenidos a lo largo del esfuerzo, 0 de las cualidades a veces innatas que hacen del maestro también un artista" (Arreola, 1979, p, 121).

Pues bien, esta es la primera forma de educación que se encuentra dentro de la obra, la otra hace referencia a la representada por don Segundo Sombra, quien es un verdadero maestro. Como dije anteriormente, el docente debe ganarse el respeto por medio del dominio de sus conocimientos y esto es lo que hace don Segundo: "asombrado miraba yo el dominio de aquel hombre, que trataba a mi petizo como a un cordero gaucho" (Güiraldes, 1985, p. 75). El profesor se gana el cariño y la admiración de los estudiantes por medio de lo que sabe y de la manera como lo enseña, como en este caso: don Segundo es un 
hombre callado quien, sin hacer alarde de sus conocimientos, guía a su ahijado para que se convierta en un verdadero hombre de pampa: "Cinco años habían pasado, sin que nos separáramos ni un solo día, durante nuestra penosa vida de reseros. Cinco años de ésos hacen de un chico un gaucho, cuando se ha tenido la suerte de vivirlos al lado de un hombre como el que yo llamaba mi padrino. Él fue quien me guió pacientemente hacia todos los conocimientos de hombre de pampa" (Güiraldes, 1985, p. 82). Sin duda, Fabio Cáceres admira a don Segundo Sombra, pues desde el principio vio en él cualidades dignas de imitar, vio en don Segundo a ese hombre que le podía ofrecer conocimientos que le permitieran mejorar sus condición de ser humano, de hombre de pampa, en este caso. Así mismo, hoy en día el estudiante debe ver en su profesor a ese hombre que admira, ese hombre que le permitirá mejorar como ser humano, pues durante sus años de escolaridad le aportará grandes conocimientos que fortalecerán la formación de su ser.

Por otra parte, el docente debe formar ciudadanos, pero ¿en qué consiste esta educación? Educar a un ciudadano hace referencia a la formación "de un hombre que pueda intervenir, de alguna manera, e incidir conscientemente en el destino de la sociedad en que vive" (Zuleta, 1995, p. 101). No se trata de limitar la clase a la simple exposición del conocimiento y pensar que con ello se está transformando la vida de los estudiantes, el docente debe preocuparse por formar seres integrales que estén llenos de un espíritu crítico, debe proponerse llevar al estudiante a decidiry a intervenir en las decisiones de la sociedad en que está inmerso. Además, el docente no debe contentarse con la simple exposición aislada de sus saberes, sino que debe tratar de incursionar en la vida del alumno para hacer de él un ser íntegro que pueda participar en las diferentes esferas sociales, así como lo hace el padrino de Fabio:

También por él supe de la vida, la resistencia y la entereza en la lucha, el fatalismo de aceptar sin rezongos lo sucedido, la fuerza moral ante la aventuras sentimentales, la desconfianza para con las mujeres y la bebida, la prudencia entre los forasteros, la fe entre los amigos.

Y hasta para divertirme tuve en él a un maestro, pues no de otra parte me vinieron mis floreos en la guitarra y mis mudanzas en el zapateo. De su memoria saqué estilos, versadas, y bailes de dos, e imitándole llegue a poder escobillar un gato 0 un triunfo y a bailar una huella o un prado. Coplas y relaciones sobraban es su haber para hacer sonrojar de gusto o de pudor a un centenar de chicas.

Pero todo eso no era sino un resplandor de sus conocimientos, y mi admiración tenía donde reposarse a diario. (Güiraldes, 1985, p. 83).

Para llevar a cabo esta labor, es decir, formar ciudadanos, el docente, al igual que don Segundo Sombra, debe ser un hombre íntegro: ¿quién dijo que solo el docente de lengua castellana debe leer textos referentes a la lengua castellana o que solo el docente de filosofía debe enseñar a pensar, en el mejor de los casos, 0 , en el peor, repetir qué es un silogismo? Los docentes creen que su labor termina cuando el timbre suena y que durante sus horas de clase solo deben impartir los conocimientos pertenecientes a su materia, sin interesarse por relacionarlos con la vida del estudiante o por hacer que por medio de ellos el alumno desarrolle su capacidad de razonamiento. Pero icómo se va a lograr esto si en las aulas de clase tenemos a docentes de español y literatura que no les gusta leer y escribir 0 a docentes de matemáticas que no encuentran en ella una verdadera necesidad? ¿Cómo va a enseñar a leer un docente si es una pasión con la que no cuenta? Ante esta problemática, el profesor debe repensar la forma como está ejerciendo su labor, pues no se trata de llegar todos los días a llenar el tablero de cifras inoportunas que el estudiante no entiende 0 no le interesa entender. El docente diariamente debe fortalecer su aprendizaje $y$ enriquecer sus conoci-mientos para así afrontar de una manera más pertinente la labor social tan importante que desarrolla: "el formador de hombres, según EduardSpranger, se propone la tarea más alta que es posible imaginar: intervenir en la formación de la conducta ajena mediante el ejemplo de la conducta propia. Y esto es mucho más difícil que tallar hermosas maravillas técnicas" (Arreola, 1979, p. 122).

Ante esta idea del docente como formador de ciudadanos Estanislao Zuleta dice que debe existir una educación filosófica, la cual "debe poner el acento en la formación. Esto significa que la enseñanza de todo lo que nosotros llamamos materias debe tender a darse en forma filosófica, es 
decir, como pensamiento, y no como conjunto de información" (1995, p. 102). Por consiguiente, cada clase, sin importar si es de biología, de sociales o de filosofía, debe aportar al desarrollo del pensamiento del estudiante, cada clase debe servirle para construir sus propios puntos de vista y para crearse una perspectiva de vida. Dice Zuleta (1995, p. 102 - 106) que enseñar filosóficamente una materia es llenarla de sentido, es decir, no quedarse en la recepción de información, sino cuestionarla, problematizarla, saber, por ejemplo, para qué sirve realmente el cálculo en la vida cotidiana, qué repercusiones tiene en la sociedad su disposición geográfica o cuáles han sido las diferentes concepciones del mundo en la literatura 0 en la historia. No se trata de llegar al aula con un listado de fechas, autores, formulas 0 fenómenos naturales que no le ofrecen nada importante al estudiante, se trata de enseñar a pensar, a razonar. Al respecto traigo a colación un hermoso texto de Ernesto Sábato: "Sobre algunos males de la educación", en el cual cuenta sus experiencias en su recorrido por La Patagonia y de este cito lo siguiente:

Hace poco leí la clase escrita de un alumno aplazado porque había olvidado no sé qué porcentaje de esa famosa lista de puntas y cabos. También he ojeado un prestigioso texto de literatura que actualmente se usa en nuestros colegios, y sólo en el capítulo dedicado al siglo XVIII español recorre un catálogo de nombres por cuya ignorancia yo sería castigado por un profesor puntilloso: Diego de Torres, Emilio Lobo, Ramón de la Cruz, García de la Huerta, Cadalso y Vásquez, Álvarez Cienfuegos [...] ; con sus correspondientes fechas de nacimiento y muerte, con los títulos de sus libros, libros que nadie de mi conocimiento conoce, sin que por eso sufra su condición de persona culta. (1996, pp. 81-82).

Este flagelo académico referenciado por Sábato es una endemia del docente a lo largo y ancho del continente y perpetúa modelos de evaluación en donde la memorización cobra su más grande presencia. En ello no importa la formación sino la información y es muy contrario al tipo de enseñanza, en donde el docente procura crear en el alumno la necesidad de adquirir el conocimiento. Lo que Sábato plantea es que si no existe una necesidad no existirá tampoco un verdadero proceso de aprendizaje, ya que todos lo aprendido se borrara de la cabeza del estudiante inmediatamente después de su ceremonia de graduación, si es que esto no ocurre antes.

Durante la novela, don Segundo Sombra nunca obliga a su discípulo, por medio de una nota o de un castigo, a adquirir un conocimiento, sino que por medio de las experiencias y vivencias diarias del joven deja que él mismo descubra la necesidad de aprender, no solo a domar un caballo, sino a ser prudente, a ser buen bailarín, a disfrutar de las historias legendarias o a luchar por lo que desea. Fabio no se aprende las lecciones de su padrino de memoria, sería imposible e inútil memorizar una tarde de arreo para repetirla semanas después, puesto que no se presentarían las mismas circunstancias: no contaría con el mismo números de reses, no recorrería la misma distancia ni el mismo camino, no llovería a la misma hora o no contaría siempre con la misma tranquilidad del primer arreo, lo que quiere decir, que el estudiante no siempre se encontrará en su quehacer con los mismos obstáculos cognitivos, con las mismas dudas o inquietudes. Fabio lo que hace, incentivado por su padrino, es encontrar en las actividades que emprende la necesidades que lo llevan a ellas, para, de esa manera, poder reflexionar sobre su utilidad y sobre la manera cómo debe proceder ante ellas, siempre utilizando su racionalidad, nunca memorizando pasos. Pero en el aula no se enseña a reflexionar sobre los beneficios de un saber, todos, tanto alumnos como profesores, están tan preocupados por la nota y por memorizar para el examen que se olvidan de las necesidades que deben crearse para que exista el verdadero aprendizaje. EI docente no debe hacer de la calificación cuantitativa la base de la enseñanza, sin detenerse a incentivar en los estudiantes la búsqueda de necesidades a la hora de afrontar una tarea o actividad, debido a que:

La educación recurre entonces al mecanismo de la nota, al de la competencia o al de la promoción. En el mecanismo competitivo el fracaso de uno es el existo de otro. Hay otros a los que les puedo ganar y que me pueden ganar. El aprendizaje no está motivado por el deseo de saber algo que se nos ha hecho necesario, inquietante, interesante, 0 por la solución de una incógnita que nos conmueve, sino por la nota, la promoción, la competencia, el miedo de perder el año y ser regañado o penado (Zuleta, 1995, p. 108). 
Por razones como esta, es que tenemos una educación en donde no se pueden reconocer realmente quiénes son los verdaderos estudiantes que están fortaleciendo su espíritu filosófico, ya que el joven que saca mejor nota, es decir, el que se aprende de memoria todos los planteamientos e informes del docente, no es, seguramente, el que está aprendiendo a pensar por medio de la matemática, de la literatura o de la filosofía, no es quien, en últimas, logrará pensar por sí mismo. Así que deben crearse necesidades, debido a que algo sumamente importante en ellas es que permiten crear seres autónomos como lo es Fabio Cáceres, lo cual no es tan fácil de lograr al ver la nota como meta final. En palabras de Estanislao Zuleta: un estudiante autónomo es un filósofo, es decir, es un "hombre que quiere saber; el hombre que aspira a que el saber sea la realización de su ser; el hombre que quiere saber por qué hace algo, para qué lo hace, para quién lo hace; el hombre que tiene una existencia de autonomía." (1995, p. 25 - 26). Después de doce años de escolaridad no se deberían graduar hombres ingenuos e incompletos, sino filósofos, todo el que haya pasado por un plantel educativo debería tener este título, puesto que debería haber cambiado su forma de pensar como lo hace Fabio: "De ningún modo volvería a hacer el vago por las calles aburridas. Yo era, una vez por todas, un hombre libre que ganaba su puchero, y más bien viviera como puma, alzado en los pajales, que como cuzco de sala entre las faldas hediondas de sahumerio eclesiástico y retos de mandonas bigotudas" (Güiraldes, 1985, p. $48-49)$.

En consecuencia, el docente debe reflexionar y preguntarse el para qué de la memorización de conceptos, de textos 0 de fórmulas, si son conocimientos que se pueden obtener abriendo un libro, un cuaderno de apuntes o simplemente navegando en internet. ¿Para qué debe memorizar el estudiante el himno nacional de su país, si primero no comprende en qué momento de la historia se originó y por qué motivo?; ¿para qué memoriza la fecha en la que Gabriel García Márquez obtuvo el Premio Nobel de Literatura, si no comprende la importancia de su obra?; ¿para qué se aprende la famosa fórmula de velocidad es igual a masa por aceleración o que ? (pi) es igual a 3.1416, si todavía no ha entendido para qué le va a servir en la vida? Después de cuestionar esta manera de aprendizaje, el docente se dará cuenta que, como lo asegura William Ospina, "dado que todo lo que se memoriza finalmente se olvida, más vale enseñar procedimientos y maneras de razonar que respuestas que puedan ser copiadas" (2012, p.20). De este modo procede don Segundo Sombra, enseñando a su ahijado a razonar, ya que en ningún momento Fabio memoriza paso por paso lo que debe hacer para domar su caballo, sino que aprende por medio del hacer. Así, quien desee aprender a escribir debe escribir, no memorizar un decálogo del escritor; quien desee conocer la obra de un autor debe leer sus escritos, no memorizar su biografía; quien tenga interés en aprender a bailar debe hacerlo constantemente, no memorizar pasos de una coreografía, y señalo el baile porque el estudio es tan placentero como el baile. Solo así se adquiere el saber, puesto que, como lo retoma William Ospina de Nietzsche, "sólo sabemos lo que sabemos hacer" (2012, p. 47).

Del mismo modo, recurrir a la nota como fin único y primordial de la educación es hacer de esta una competencia, en donde el docente solo debe buscar al mejor, en donde solo uno puede ser el mejor. Esto no debería ser así, debido a que al establecerse la existencia de alguien con mejores capacidades se está jugando con la autoestima y el buen rendimiento académico de los demás. "No toda formación tiene que buscar individuos superiores, hay por lo menos un costado de la educación cuyo énfasis debería ser la convivencia y la solidaridad antes que la rivalidad y la competencia" (Ospina, 2012, p. 22). Así como es educado Fabio, a quien su docente nunca le enseña a imponerse ante los demás, ni a buscar entre sus compañeros de arreo debilidades sobre las cuales pueda demostrar sus capacidades, deben educarse todos los individuos que ingresen al sistema escolar, puesto que debería ser un interés común la formación de hombres sociables y solidarios.

Otro aspecto importante que obstaculiza el verdadero aprendizaje y la formación del ser es pensar que "la educación es un sistema de prohibición del pensamiento, trasmisión del conocimiento como un deber, el conocimiento como algo dado, petrificado" (Zuleta, 1985, p. 89); es decir, que para mejorar la educación es importante y trascendental dejar de pensar que el conocimiento es uno solo, dogmático y verdadero. Don Segundo Sombra en ningún 
momento entrega el conocimiento como algo establecido a su ahijado, primero deja que él mismo se acerque a lo que quiere saber, que trate de aprender por medio de sus propias experiencias, para después guiarlo hacia el conocimiento, como sucede cuando Fabio trata de domar por primera vez a su petizo: don Segundo deja que el muchacho se enfrente al objeto de conocimiento para después guiarlo, por lo tanto, en ningún momento él le ahorra a su estudiante la tarea de experimentar para pensar, como sucede actualmente en la educación, en donde "el estudiante se puede caracterizar como la personificación de una demanda pasiva. 'Explíqueme', 'deme elementos', '¿cuáles son los prerrequisitos para esta materia?', '¿cómo estamos en la escalera?', '¿cuántos años hay que hacer para empezar a leer el Quijote?'. No hay que hacer ningún curso, hay que aprender a pensar" (Zuleta, 1985, 89). Esto es a lo que tiene que ir el estudiante al colegio, no a memorizar como un autómata y a repetir modelos de conducta, sino a desarrollar su capacidad de pensamiento, para que en el futuro pueda intervenir coherentemente en la sociedad.

Pero ¿cómo podría impartirse una educación como la que don Segundo le da a su ahijado? Este hombre de pampa inicia su labor de educador no imponiéndose, sino permitiendo que su estudiante se le acerque, es decir, que se preocupa por crear un vínculo de confianza que permite que los próximos acercamientos sean más amenos y gratos. No se trata de que el profesor se haga amigo de los estudiantes, sino de hacer que ellos vean en él esa persona en la que pueden confiar, a la que le pueden preguntar sin miedo 0 a la que pueden recurrir si tienen algún problema, ya sea de aprendizaje o de otra índole personal. Luego, don Segundo permite que Fabio observe su labor de domador y permite luego que este haga parte de sus conversaciones y escuche sus lecciones: "Medio dormido me acomodé en un rincón, cerca de un grupo formado por don Segundo, Valerio y Goyo, que quería aprender del oficio, y escuchaba en lo posible los comentarios del trabajo brutal, lleno de sutilezas y mañas" (Güiraldes, 1985, p. 47). Después, el muchacho insiste en querer domar a su petiso, con lo cual queda en evidencia para don Segundo esa curiosidad y ese interés que el alumno a despertado en la labor que debe desempeñar, por lo tanto, decide intervenir y ayudar al muchacho para que aprenda las mañas del oficio, sin dejar escapar aquella buena oportunidad que tiene para instruir a su ahijado, sin que esto se convierta en una obligación para el muchacho: "Güeno. Yo te vi a ayudar pa que no andés sirviendo de diversión a la gente. Aquí nadie nos va ver, y vah'hacer lo que yo te mande" (Güiraldes, 1985, p. 75), e inmediatamente inicia con paciencia las lecciones de resero.

Del mismo modo, durante el camino que tiene que recorrer en busca del conocimiento, el muchacho tiene que vivir sin ninguna compasión o lástima todos los obstáculos que la vida de resero le presenta: "La lluvia se precipitó, interceptándonos el horizonte, los campos y hasta las casas más cercanas" (Güiraldes, 1985, p. 78). Sin importar que sea un aprendiz del oficio y que tan solo cuente catorce años de edad debe, como todos, tratar de calmar a la tropa que amenaza con desordenarse y dispersarse por culpa de la tormenta, debe tratar por sus propios medios de superar los obstáculos que en su vida de gaucho se impongan. Luego de que el muchacho ya ha recorrido y ha aprendido por medio de la imitación varios saberes necesarios para ser un verdadero hombre de pampa, don Segundo le permite que asuma la tareas de resero, esta vez, sin su ayuda, sin su supervisión, lo cual le servirá para corroborar lo que realmente sabe: "Antes de aclarar salimos. Me habían dado por compañeros dos mocetones de unos veinte años" (Güiraldes, 1985, p. 136), jóvenes que por su corta edad apenas se iniciaban en el arte del rodeo. Junto a estos nuevos compañeros, Facio expande sus horizontes, sus conocimientos: "Nuevas curiosidades para mí: los médanos, el mar." (Güiraldes, 1985, p. 136). Luego de esta difícil prueba, de la que sale con la islilla quebrada, don Segundo le permite al muchacho tomar sus propias decisiones y adquirir sus propias responsabilidades. Fabio decide domar doce potros bayos, pues tiene la necesidad de obtener ganancias después de haber perdido varios de sus caballos. Ante esta nueva empresa, don Segundo decide ayudarlo para reforzar los conocimientos que ha adquirido a su lado: "Los ensillaba apurado, como en un sueño, siguiendo al pie de la letra los consejos de don Segundo, que, al lado mío, ya alcanzándome alguna pilcha, ya apadrinándome, me guiaba paso a paso, sapientemente" (Güiraldes, 1985, p. 197). Después de este trabajo, Fabio, el joven que no sabía nada, empieza a recibir la recompensa por su 
disciplina y desempeño como resero: el patrón de la estancia donde domó los doce caballos le ofrece que se quedé como domador, pues ha demostrado con su labor lo bien preparado que se encuentra. Es en este preciso momento, cuando Fabio empieza a tomar las decisiones que irán marcando el camino que en su vida quiere recorrer: aunque en algún momento de la obra el joven se separa de su padrino, esta vez decide que aún no es hora de apartarse de ese hombre que le ha enseñado todo, que aún debe recorrer una parte del camino junto a él, pues es consciente de que todavía le faltan cosas por aprender.

Según el recorrido que he realizado sobre la labor docente de don Segundo Sombra, puedo relacionar esta forma de aprendizaje con la que expone Aníbal Ponce, la cual se presentaba en las tribus indígenas antiguas:

Gracias a una insensible y espontánea asimilación de su contorno, el niño se iba conformando poco a poco dentro de los moldes reverenciados por el grupo. La diaria convivencia con el adulto lo introducía en las creencias y en las prácticas que su medio social tenían por mejores. Desde las espaldas de la madre, colgado dentro de un saco, asistía y se entremezclaba a la vida de la sociedad, ajustándose a su ritmo y a su norma, y como la madre marchaba sin cesar de un lado para otro y la lactancia duraba varios años, el niño adquiría su primera educación sin que nadie lo dirigiera expresamente. (Letourneau, citado en Ponce, 1981, p. 10 - 11)

Precisamente, esto es lo que debería presentarse en nuestra educación: sumergir al estudiante en un entorno, ya sea el de la lectura, el de la matemática, el de la física 0 el de cualquier otra materia que se dicte en los centros educativos. El entorno de Fabio Cáceres es la pampa, sin ese espacio no hubiera logrado nunca ser un verdadero gaucho, lo mismo pasa con los jóvenes, si no están en un entorno de lectura, jamás lograran ser verdaderos lectores; si no están en un entorno de pensamiento matemático, tampoco podrán en un futuro resolver problemas de la vida cotidiana por medio de la matemática. Del mismo modo, si el estudiante aprende a partir de la convivencia con el docente y de la imitación de sus actos, como sucede en el aprendizaje de Fabio, entonces el docente que desee enseñar algo debe realizarlo: un estudiante no se motivará a escribir si no ve que su profesor escribe, no se motivará a leer si aquel que le está enseñando no lee. Principalmente a eso hago referencia cuando digo crear entornos, a que el educador haga parte de ese aprendizaje, pues el también debe estar dispuesto a aprender. También hago referencia a crear aulas de lectura, de llevar a los estudiantes a las bibliotecas, a utilizar los laboratorios a conciencia, a hacer del aula de clase un lugar más ameno, para que el estudiante esté más cerca del conocimiento. En este momento recuerdo una experiencia que tuve con unos estudiantes de San Gil, quienes pedían a sus profesores que por favor los llevaran al aula de lectura, en la cual podían encontrar un entorno más adecuado para gozar de la literatura, pues esta, además de estar rodeada de buenos textos como Madame Bovary, María, cuentos de Julio Cortázar, entre otros, estaba decorada con muchas mariposas amarillas en honor a nuestro célebre escritor Gabriel García Márquez. De eso se trata, de acercar a los alumnos al conocimiento, no debemos creer que las decoraciones y los colores solo son para niños de primaria, los estudiantes de bachillerato también se entusiasman al ver la creatividad y, mucho más, al hacer parte de ella. Tampoco debemos escondernos detrás del pretexto de que no hay recursos, ya que para enseñar a leer, a escribir, a solucionar problemas, a comprender el comportamiento humano, en suma, para enseñar a pensar, no es necesario un video beam, una cámara digital 0 una tablet, el docente que desea enseñar de verdad se vale de las cosas más simples para hacer de ellas herramientas útiles que le permitan formar a los estudiantes.

Por otra parte, el docente debe, como lo hace don Segundo, crear un vínculo de confinza con sus estudiantes. Si bien es cierto que para conservar el trato de docente - estudiante deben mantenerse ciertos límites que garanticen el respeto por parte de los alumnos, también es cierto que el docente debe permitir una "relación de cordialidad" (Ospina, 2012, p. 28), puesto que el diálogo que ella favorece es la mejor forma de compartir el conocimiento. A partir de esta vinculo, el docente debe, como he señalado que lo hace don Segundo, guiar al estudiante por el camino del conocimiento, permitiéndole avanzar por sus propios medios, sin evitarle la gratificante tarea de pensar, pues no se trata de dar fórmulas y cuestionarios que resuelvan todas las inquietudes, ya 
que "la educación no debe consistir tanto en llenarnos de certezas como en orientar y alimentar nuestras búsquedas" (Ospina, 2012, p.40). El docente debe facilitarle elementos al estudiante que le permitan avanzar por sí mismo, aprendiendo de sus propios errores y tropiezos. De esta forma, el estudiante se dará cuenta de que el camino del saber es pedregoso y está lleno de altibajos, los cuales le exigen su esfuerzo y su disciplina para superar las dificultades que aparezcan durante el aprendizaje, como lo deja ver Fabio por medio de las siguientes palabras:

Sabía que si en gran parte se resiste por tener hecho el cuerpo a la fatiga, más se resiste por tener hecha la voluntad a no ceder. Primero el cuerpo sufre, después de asonsa, y va, como sin tomar parte, adonde uno lo lleva. Después, las ideas se enturbian; no se sabe si se llegará pronto o no se llegará nunca. Más tarde las ideas, tanto como los hechos, se van mezclando en una irrealidad que desfila burdamente por delante de una atención mediocre. A lo último, no queda capacidad vital sino para atender a lo que uno se propone sin desmayo: seguir siempre. $Y$ se vive nada más que por eso y para eso, porque todo ha desaparecido en el hombre fuera de su propósito inquebrantable. (Güiraldes, 1985, p. 217 -218).

Después de que el estudiante es consciente del camino que debe recorrer para alcanzar el conocimiento, el docente debe empezar a soltarlo para que él mismo se enfrente al saber y empiece a elegir lo que quiere conocer, lo que quiere leer, los fenómenos que quiere comprender, los problemas que quiere resolver y las capacidades que quiere fortalecer. En últimas, el estudiante a medida que profundice en sus búsquedas y cavilaciones se dará cuenta de que el conocimiento nunca finaliza, porque no existen verdades absolutas, porque existen preguntas sin respuestas o porque aún faltan hechos por explorar 0 descubrir. Se dará cuenta que el mundo del conocimiento es infinito y que estará inmerso en él por el resto de su vida, puesto que en el colegio se adquiere la capacidad de buscar, de inquietarse, de cuestionarse, de pensar, lo cual le sirve para continuar en la vida descubriendo la grandeza del conocimiento.

Por consiguiente, si se lleva a cabo una educación como la planteada anteriormente se tendrán verda- deros hombres pensantes, que en vez de estar satisfechos y conformes con lo que creen saber, salen del colegio a seguir fortaleciendo sus capacidades, ya sea en una universidad, en un instituto de educación superior o en la vida misma. De este modo, se forman seres para dudar, no para estar convencidos; seres para cuestionar, no para tener fe; seres para debatir, no para aceptar; seres para preguntar, no para responder. En definitiva, se forman seres para pensar, como sucede con Fabio Cáceres, que además de convertirse en un gaucho, llega a dudar y reflexionar acerca de las cosas y los sucesos que lo rodean, como ocurre en el capítulo $X X V I$, en donde, después de ver a su amigo Antenor matar a un hombre, reflexiona sobre asuntos de la vida: "¿no se es dueño entonces de nada en la propia persona? ¿Un encuentro inesperado puede presentarse, así, en forma de destino, para desbaratarlo a uno en su propio modo de ser? ¿Somos como creemos, o vamos aceptando los hechos a manera de indicaciones que nos revelan a nosotros mismo?" (Güiraldes, 1985, p. 212). Su capacidad de pensar también se puede ver en estas conclusiones: "Me dije que no éramos nadie. [...] ¡Qué cantidad de estrellas! ¡Qué grandura! Hasta la pampa resultaba chiquita" (Güiraldes, 1985, p. 127). Afirmaciones que a simple vista parecen banales, pero que tienen un gran contenido filosófico, ya que hacen referencia a esa pequeñez del hombre ante el universo, esto es, ante el mundo del conocimiento.

\section{Conclusión}

Según lo dicho hasta el momento, a partir de la relación que establezco entre la pedagogía y Don Segundo Sombra, puedo decir que actualmente nos encontramos ante una educación comprometida, no con el estudiante, claro está, sino con unos intereses sociales, económicos y políticos preestablecidos. Aníbal Ponce, en su texto Educación y lucha de clases (1981), hace un análisis del estado de la educación según la división de la sociedad en clases y se remite a las culturas antiguas, como la egipcia 0 las indígenas, para explicar el cambio que la educación ha tenido a los largo de los años. Me remito a este autor $y$ a sus planteamientos porque en ellos encuentro una razón muy coherente acerca del porqué actualmente la educación se encuentra, como dije anteriormente, comprometida. Aníbal Ponce (1981, p. 9-26) asegura que después de que 
aparecieron las clases sociales la educación dejó de ser un interés común a todos los integrantes de la civilización, es decir, anteriormente la educación tenía unos fines implícitos que favorecían los intereses de toda la comunidad, que al no tener diferencias luchaban por los mismos derechos educativos para sus hijos, quienes aprendían "para la vida por medio de la vida" (Ponce, 1981, p. 11) sin ningún tipo de castigo 0 de negación a la formación del espíritu racional. Con la aparición de las diferencias sociales, que se dio gracias al "escaso rendimiento del trabajo humano y la sustitución de la propiedad común por la propiedad privada" (Ponce, 1981, 15), la educación empieza a llenarse de intereses comunes a las clases privilegiadas:

Semejante transformación tienen para nosotros una importancia grande. En la sociedad primitiva la colaboración entre los hombres se fundaba en la propiedad común y en los vínculos de sangre; en la sociedad que comenzó a dividirse en clases, la propiedad se hizo privada y los vínculos de sangre retrocedieron ante el nuevo vínculo que la esclavitud inauguró: el que engendra el poder del hombre sobre el hombre. Desde ese instante los fines de la educación dejaron de ir implícitos en la estructura total de la comunidad. 0 para decirlo de otra forma: con la desaparición de los intereses comunes a todos los miembros iguales de un grupo, y su sustitución por intereses distintos, poco a poco antagónicos, el proceso educativo hasta entonces único se escindió. (Ponce, 1981, p. 18 - 19)

Ante esta situación de sumisión, quienes ostentaban el poder buscaron en la religión y en la coerción el modo de mantener a la plebe lejos de una posible rebelión, esto es, apartaron al pueblo del pensamiento autónomo. Como lo expone Aníbal Ponce (1981, p. 9 - 26) las fuerzas dominantes buscaron en las divinidades mantener a sus esclavos 0 inferiores dentro de la fe ciega que profesaba que la organización de la sociedad estaba dispuesta por un orden superior, que les daba a los mandatarios el poder para subyugarlos. Es así como encontramos el estado de nuestra educación actual, un sistema en donde "el tipo de persona que se forma es una tuerca que debe ajustar muy bien en alguna parte del engranaje productivo" (Zuleta, 1995, p. 101), en otras palabras, un individuo entrenado para favorecer los intereses productivos y económicos de un tercero. Al Estado, que, según Ponce (1981, p. 23 - 24), aparece para conservar los intereses comunes de los gobernantes, no le conviene fomentar en la sociedad el espíritu filosófico propuesto por Estanislao Zuleta, puesto que para sus intereses sería un riesgo tener seres políticos que cuestionen las decisiones del Estado o que duden acerca de los diferentes planteamientos políticos que establecen diariamente los que ejercen el poder.

Ante esta situación el docente debería ser quien se interese por ejercer un cambio en el pensamiento de la sociedad, pues él es quien está en constante contacto con los jóvenes, que son los individuos que en el futuro van a tomar las decisiones políticas y económicas que mantendrán o cambiarán la situación del país. Es muy cierto que los jóvenes no son fáciles de formar, ya que están influenciados por la música y la televisión, que lo único que hacen es mal formar su carácter por medio de las conductas que imponen las novelas, los programas de farándula, los documentales, los realities show, el reggaetón, entre otras manifestaciones del mundo actual, tal como lo expone Vargas Llosa en su estupendo libro La civilización del espectáculo (2012), pero exactamente ahí es donde está la labor del docente: debe dialogar con el estudiante, para mediar entre su entorno y lo que le ofrece la escuela. Por otra lado, también se debe mediar en la adquisición de conocimientos, puesto que el estudiante llega al aula de clase con unos saberes previos, entonces, el docente no debe embutirle al joven el saber, sino que se trata de "cambiar una cultura experimental, de derribar los obstáculos amontonados por la vida cotidiana" (Bachelard, 1979 , p. 21). En otras palabras, la tarea del docente es "critica[r] y desorganiza[r] el conjunto impuro de las intuiciones básicas" (Bachelard, 1979, p. 21). Una lectura no sería significativa para el estudiante si no se cuestiona por medio de ella sus conocimientos 0 sus perspectivas de vida, un ejercicio de geometría no sería trascendental si este no pone en duda los conocimientos previos que ha adquirido el estudiante en su vida.

El docente debe ser consciente de la importancia que en la sociedad tiene su cargo. Aunque la profesión esté tan degradada en el pensamiento colectivo, el docente debe luchar por realizar cada día un cambio que contribuya a mejorar su quehacer. Para lograrlo 
es importante, ante todo, que admita sus errores, ya que como lo señala Gaston Bachelard, "un educador no tiene el sentido del fracaso, precisamente porque se cree un maestro" (1979, p. 21), actitud que se convierte en uno de los más grandes obstáculos para el surgimiento de una nueva manera de enseñanza que contribuya a formar auténticos ciudadanos. Al admitir su error, el profesor se da cuenta de que su labor no consiste en educar a sus alumnos para que reciban un diploma en la ceremonia de graduación, sino que su labor es formar para la vida, como lo he venido señalando a lo largo del texto. El cuanto de Horacio Quiroga, titulado Cuento para estudiantes, presenta un excelente ejemplo de aquel docente que pretende siempre tener la razón y el dominio del saber y de la clase, motivo por el cual nunca transforma su modo de trasmitir el conocimiento, convirtiéndose, así, en un obstáculo del mismo.

En definitiva, don Segundo Sombra es una idea, sí, esa idea que de la docencia se debe tener. Todo profesor debe actuar como él: guiar al estudiante por la senda del conocimiento, darle herramientas que le permitan profundizar en el saber y superar los diferentes inconvenientes que se le puedan presentar, permitirle pensar y decidir por sí mismo, hasta hacer de él un ser autónomo. El docente no debe tan solo dirigir el recorrido que el estudiante hace en la constante búsqueda del saber, sino que debe recorrer una parte del camino con él, así como don Segundo Sombra acompaña a su ahijado Fabio durante una parte de su vida.

\section{Bibliografía}

Arreola, J. (1979). La palabra educación. México. Sep Diana.

Bachelard, G. (1979). La formación del espíritu científico. Bogotá, Siglo XXI editores, S.A.

Güiraldes, R. (1985). Don Segundo Sombra. Barcelona, Bruguera.

Ospina, W, (2012). La lámpara maravillosa. Cuatro ensayos sobre la educación y un elogio de la lectura. Medellín, Random House Mondadori S.A.

Ponce, A. (1981). La educación en la comunidad primitiva. En: Educación y lucha de clases. Alkal.

Sábato, E. (1996) Apologías y rechazos. Barcelona, Editorial Seix Barral.

Zuleta, E. (1985) Sobre la lectura. En: Sobre la idealización en la vida personal y colectiva. Y otros ensayos. Bogotá, Procultura, S.A.

--------. (1995). Educación y democracia. Bogotá, Corporación Tercer Milenio. 


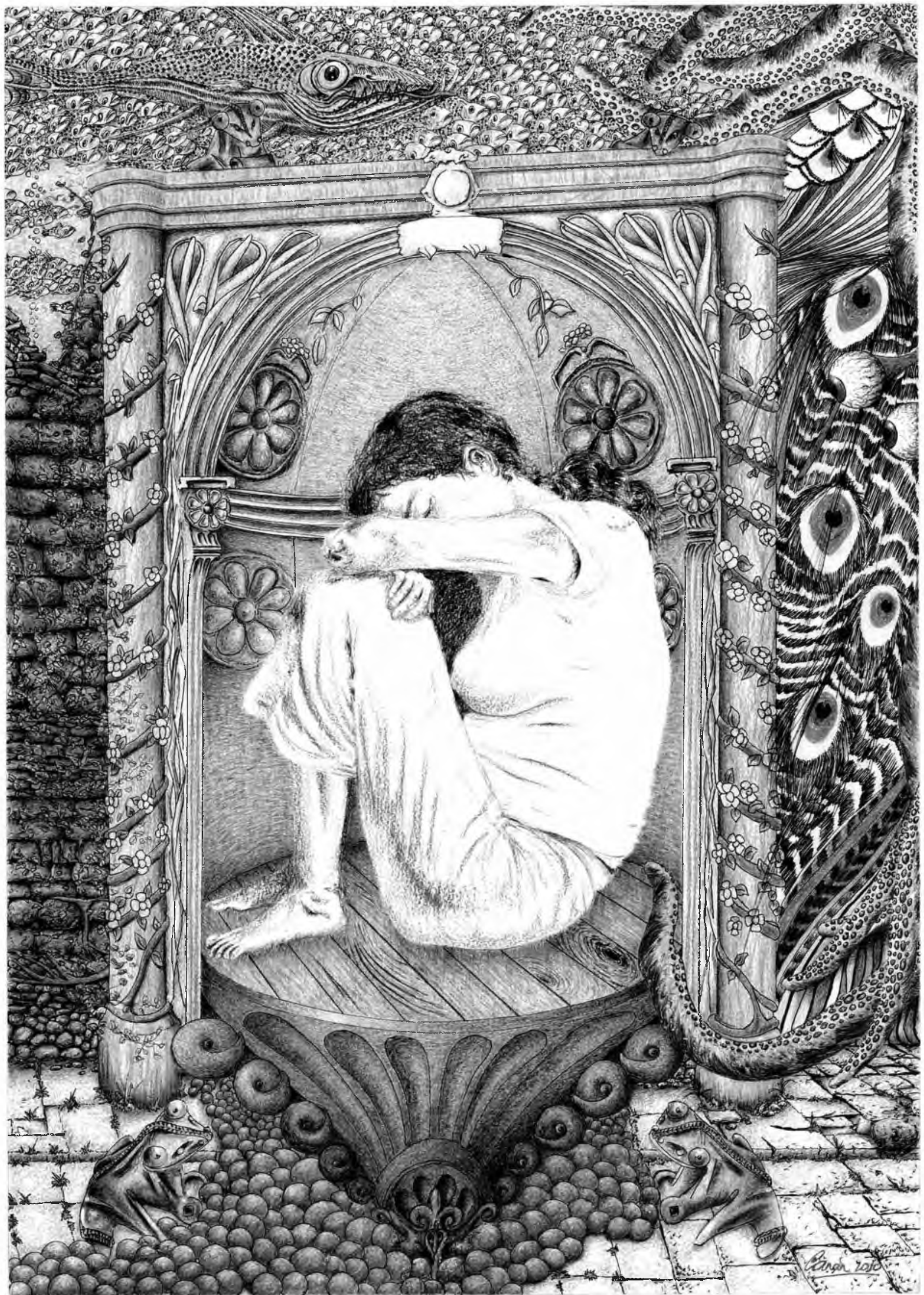

